\title{
A LOW-COST ULTRASONIC SPRAY DRYER TO PRODUCE SPHERICAL MICROPARTICLES FROM POLYMERIC MATRICES
}

\author{
Priscilla Paiva Luz, Ana Maria Pires and Osvaldo Antonio Serra* \\ Departamento de Química, Faculdade de Filosofia Ciências e Letras de Ribeirão Preto, Universidade de São Paulo, \\ Av. Bandeirantes 3900, 14040-901 Ribeirão Preto - SP, Brazil
}

Recebido em 5/4/06; aceito em 10/11/06; publicado na web em 29/8/07

\begin{abstract}
The spray-drying technique has been widely used for drying heat-sensitive foods, pharmaceuticals, and other substances, because it leads to rapid solvent evaporation from droplets. This method involves the transformation of a feed from a fluid state into a dried particulate, by spraying the feed into a hot medium. Despite being most often considered a dehydration process, spray drying can also be used as an encapsulation method. Therefore, this work proposes the use of a simple and low-cost ultrasonic spray dryer system to produce spherical microparticles. This equipment was successfully applied to the preparation of dextrin microspheres on a laboratory scale and for academic purposes.
\end{abstract}

Keywords: ultrasound spray drying; microparticle; dextrin.

\section{INTRODUCTION}

Spray drying is by definition the transformation of a pumpable feed from a fluid state (solution, dispersion, or emulsion) into a dried particulate form by spraying the feed into a hot drying medium. This technique involves evaporation from an atomized feed by mixing the spray and the drying medium. The complete process consists basically of a sequence of four steps: atomization, mixing of spray and air, evaporation, and product separation ${ }^{1-4}$.

Due to rapid solvent evaporation, the temperature of the droplets can be kept far below the drying air temperature; for this reason, spray drying can be applied to both heat-resistant and heat-sensitive materials ${ }^{5}$.

Selection of the atomizer is one of the most important choices in spray dryer design and has significant effect upon the size distribution of the final dried particles. The most important atomizer characteristics from the standpoint of product quality are uniformity of the drop size, control of drop size distribution, and spray homogeneity. Common forms of atomizers are pressure atomizers, centrifugal (wheel) atomizers, and pneumatic (two-fluid) atomizers ${ }^{2,5,6}$. However, a novel spray drying technique consisting of feeding a fluid through an ultrasonic atomizer has been developed $^{4,6-9}$, leading to smaller particle sizes.

Although it is most often considered a dehydratation process successfully employed in the drying of solutions, slurries, and pastes, spray drying is an important and widely used technology in the pharmaceutical and biochemical fields as well as in the food industry. Spray drying can also be used as an encapsulation method when it entraps "active" material within a protective matrix that is essentially inert to the material being encapsulated ${ }^{1}$. This technique is a potential process for the large scale encapsulation of fragile drugs because of the mild conditions used for this. It generally yields microparticles with high incorporation efficiency ${ }^{10}$.

Literature has reported the production of drugs microencapsulated by spray drying by means of commercially available equipment, such as the Buchi ${ }^{\circledR 10-13}$ and Labmaq $^{\circledR}$ (www.labmaqdobrasil.com.br), which implies high investiment. Therefore, in this technical note we propose

*e-mail: osaserra@usp.br simple and efficient "lab made" equipment for the production of spherical microparticles.

\section{EXPERIMENTAL}

\section{Apparatus}

The scheme of the apparatus developed to produce spherical particles from a fluid feed is shown in Figure 1. The equipment is assembled, as follows: an ultrasonic atomizer $\left(\right.$ Nevoni $^{\circledR}, 1.66 \mathrm{MHz}$ - www.nevoni.com.br) to produce nano and microdroplets, whose internal micro-compressor was replaced with an external one, namely a micro-compressor $\left(\mathrm{Vigo}^{\circledR} \mathrm{Ar}-\right.$ mini compressor for small domestic aquarium - www.vigoar.com.br), to carry out the atomized feeding; a tubular bendable (horizontal adapted to vertical) furnace with two heating zones (FT-40 series, EDG ${ }^{\circledR} 10 \mathrm{P}-\mathrm{S}$ digital controller, temperature up to $1300{ }^{\circ} \mathrm{C}-$ www.edg.com.br) as the drying chamber; a $0.2 \mu \mathrm{m}$ diameter micropored cellulose membrane (Schleicher \& Schuell ${ }^{\circledR}$ ) supported on a sintered plate filter in order to collect the particles; a vacuum pump (Heidolph ${ }^{\circledR}$ ) to separate the dried material from air; and a filter flask located inside a vessel containing cold water, used to hold the condensed vapor.

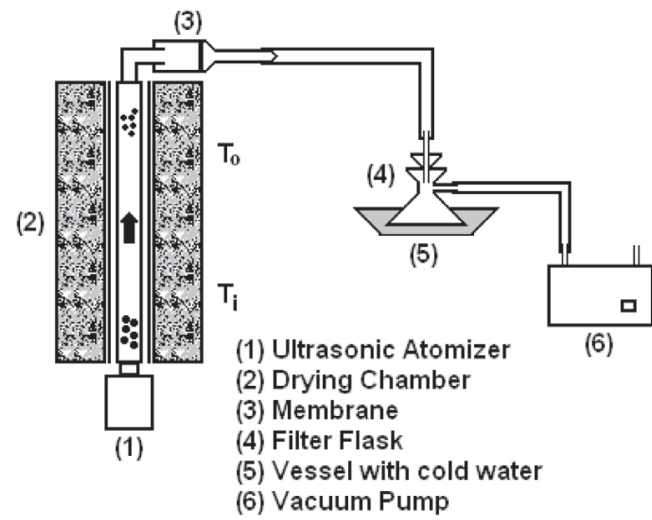

Figure 1. Scheme of the co-current ultrasound spray-drying system developed in our laboratory 


\section{Microparticles preparation and characterization}

Initially, a $20 \mathrm{mg} / \mathrm{mL}$ dextrin aqueous solution $\left(\mathrm{ACROS}^{\mathrm{o}}\right), \mathrm{Fi}-$ gure 2, was prepared. The inlet and outlet temperatures, 280 and $275{ }^{\circ} \mathrm{C}$ respectively, for the drying chamber were chosen according to the polymer is thermal features. This solution was spray dried using the ultrasonic atomizer described above.

After solvent evaporation, the dried powder collected over the membrane was morphologically characterized by scanning and transmission electron microscopies (SEM, JEOL JSM - 5200 scanning microscope, and TEM, Philips CM200 transmission microscope, equipped with Digital Spectrometer - Prism PGT Princeton Gamma Tech). Particle size was confirmed by a laser lightscattering technique (Malvern Instruments - Zeta Sizer - 3000 HS). To acquire the SEM images, the powder was dispersed in chloroform under ultrasound stirring, supported on an aluminum stub, and coated with a thin gold layer using a sputtering system after drying. In the case of TEM measurements, the powder sample was suspended in carbon tetrachloride and supported on a copper grid. For the lightscattering measurements, dry microspheres were suspended in chloroform at $0.1 \%$ (W/W), and then sonicated in the water bath, to disaggregate the particles. Ten runs of 145 seconds each were conducted. The measurement was carried out at $25^{\circ} \mathrm{C}$ with the final result being given as the average of 7 analyses. In addition, thermogravimetry and differential thermal analyses (TGA Q 600 SDT with silmultaneous record using a ceramic crucible and nitrogen atmosphere, $100 \mathrm{~mL} / \mathrm{min}$ ) were used in order to investigate the thermal stability of the produced sample. X-Ray powder diffraction data (XRD, SIEMENS D5000 diffractometer, $\mathrm{K}_{\alpha} \mathrm{Cu}$ radiation, $\lambda=$ $1.5418 \AA$, graphite monochromator) were also acquired, to evaluate the crystalline nature of the powder. Commercial dextrin was also analyzed by TGA, DTA, and XRD in order to verify if the spray drying process had changed the properties of the former polymer.

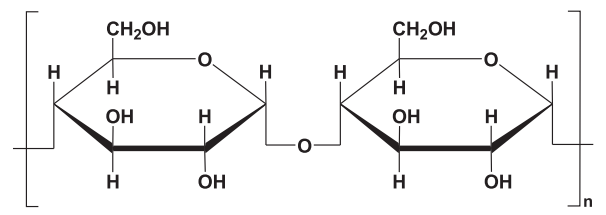

Figure 2. Dextrin structure

\section{RESULTS AND DISCUSSION}

The developed ultrasound spray drying system can be considered efficient, since $60 \%$ of the atomized feed was collected over the membrane in a dried powder form. SEM images, Figure 3, reveals that the prepared particles were spherically shaped, with a 0.2 to $2.6 \mu \mathrm{m}$ diameter size distribution. The mean average diameter determined by laser light scattering was $1.7 \mu \mathrm{m}$.

The TEM image, Figure 4, confirmed that the microparticles were

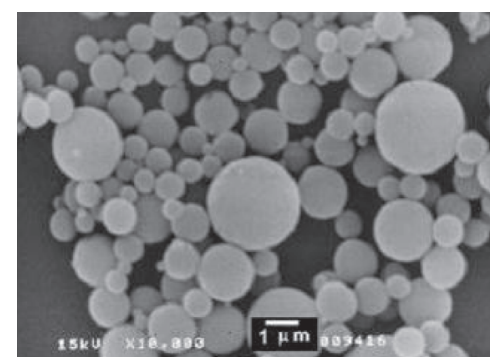

Figure 3. SEM image under $15 \mathrm{kV}$ of the dextrin sample prepared by using the developed ultrasound spray-drying technique spherical, and also gave an idea of the material density. However, it is noteworthy that during the TEM image focus, the internal structure of the spheres changed as a function of the action of the incident beam, and the underwent a kind of expansion. This expansion could be generated by the vaporization of some incorporated solvent; i.e., the carbon tetrachloride used for sample suspension. The EDS (Energy Dispersive Spectroscopy) spectrum of one particle was recorded during TEM measurements and gave evidence of the presence of $\mathrm{Cl}$ species, supporting this explanation. So, the apparent porosity of the viewed particles could be enhanced due to the incidence of the high voltage beam, and cannot be used to evaluate size porosity. Nevertheless, these images indicated that the spheres were not hollow ones.

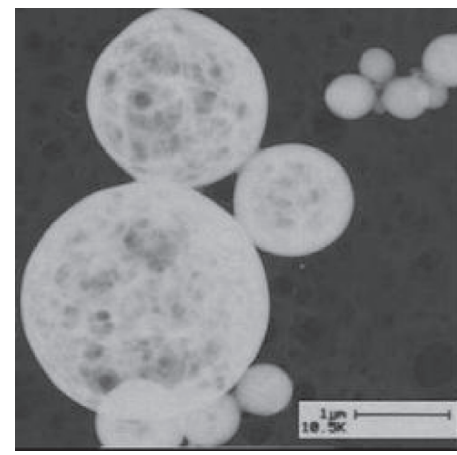

Figure 4. TEM image under $80 \mathrm{kV}$ of the dextrin sample prepared by using the developed ultrasound spray drying technique

As no diffraction peaks were observed in the XRD patterns recorded for both commercial and spray dried dextrin samples, we concluded that the non-crystalline nature of the powders did not change during the process.

From thermal analysis, Figure 5, it is possible to ensure that the dextrin is stable under the temperatures used throughout the spray drying process, since the process did not change the properties of the former polymer. DTA curves showed there was a dextrin endothermic decomposition around $300{ }^{\circ} \mathrm{C}$, corroborated by the huge weight loss observed in the TGA curves. This result agrees with those from the literature ${ }^{14}$.

Commercial Dextrin

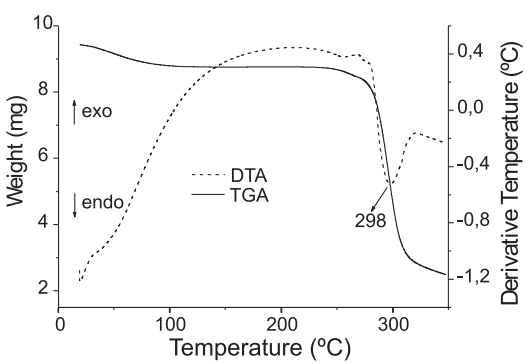

Spray Dried Dextrin

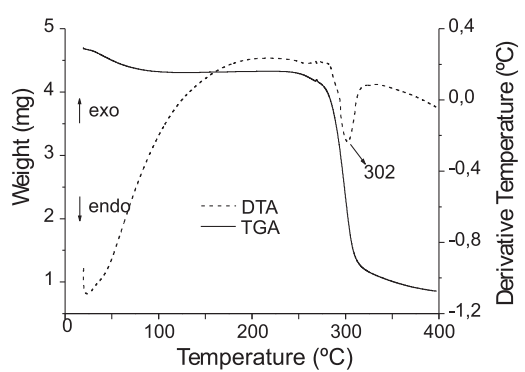

Figure 5. DTA and TGA curves of commercial and spray-dried dextrin spheres 


\section{FINAL REMARKS}

In conclusion, we have developed an inexpensive ultrasound spray drying system that can be successfully applied to the preparation of dextrin microspheres in laboratorial scale and for academic purposes. Successful encapsulation of dyes ${ }^{15-17}$ and rare earth $^{18}$ compounds are in progress in our laboratory by using the apparatus described above.

\section{ACKNOWLEDGEMENT}

Authors gratefully thank FAPESP and CNPq for financial support and scholarships. The authors are also thankful to Universidade de Franca for thermal analysis, Faculdade de Medicina de Ribeirão Preto - USP for MEV mesuraments, and Laboratório de Físico Química de Superfícies e Colóides - FFCLRP - USP, for light-scattering analysis.

\section{REFERENCES}

1. Ré, M. I.; Dry Technol. 1998, 16, 1195.

2. Mujumdar, A. S.; Handbook of Industrial Drying, $2^{\text {nd }}$ ed., Marcel Dekker: NewYork, 1995.
3. www.buchi.com, accessed on July 2006.

4. Freitas, S.; Merkle H. P.; Gander, B.; J. Controlled Release 2004, 95, 185.

5. Giunchedi, P.; Conte, U.; S.T.P. Pharma Sci. 1995, 5, 276.

6. Okuyama, K.; Lenggoro, I. W.; Chem. Eng. Sci. 2003, 58, 537.

7. Avvaru, B.; Patil, M. N.; Gogate, P. R.; Pandit, A. B.; Ultrasonics 2006, $44,146$.

8. Suh, W. H.; Suslick, K. S.; J. Am. Chem. Soc. 2005, 127, 12007.

9. Abdullah, M.; Iskandar, F.; Shibamoto, S.; Ogi, T.; Okuyama, K.; Acta Mater. 2004, 52, 5151.

10. Quaglia, F.; De Rosa, G.; Granata, E.; Ungaro, F.; Fattal, E.; La Rotonda, M. I.; J.Controlled. Release 2003, 86, 267.

11. Conti, B.; Bucolo, C.; Giannavola, C.; Puglisi, G.; Giunchedi, P.; Conte, U.; Eur. Pharm. Sci. 1997, 5, 287.

12. Gander, B.; Johansen, P.; Nam-Trân, H.; Merkle, H. P.; Int. J. Pharm. 1996, 129, 51.

13. Wang, F-J.; Wang, C-H.; J. Controlled. Release 2002, 81, 263.

14. Ramos-Sanchez, C.; Rey, F. J.; Rodriguez-Mendez, L.; Martin-Gil, F. J.; Martin-Gil, J.; Thermochim. Acta 1988, 134, 55.

15. Maestrin, A. P. J.; Ribeiro, A. O.; Tedesco. A. C.; Neri, C. R.; Vinhado, F. S.; Serra, O. A.; Martins, P. R.; Iamamoto, Y.; Silva, A. M. G.; Tome, A. C.; Neves, M. G. P. M. S.; Cavaleiro, J. A. S.; J. Braz. Chem. Soc. 2004, 15, 923.

16. Luz, P. P.; Ribeiro, A. O.; Serra, O. S.; Resumos da $28^{a}$ Reunião Anual da Sociedade Brasileira de Química, Poços de Caldas, Brasil, 2005.

17. Luz, P. P.; Pires, A. M.; Serra, O. S.; Resumos da $29^{a}$ Reunião Anual da Sociedade Brasileira de Química, Águas de Lindóia, Brasil, 2006.

18. Nassar, E. J.; Serra, O. A.; Quim. Nova 2000, 23, 16. 